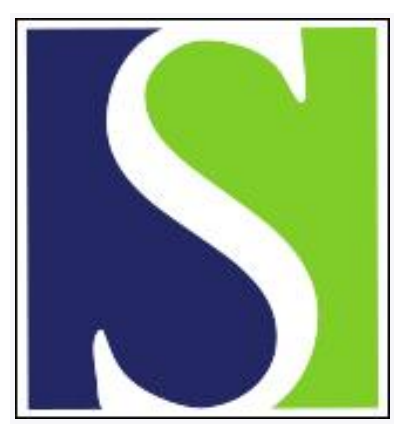

Scand J Work Environ Health 2003;29(1):51-59

https://doi.org/10.5271/sjweh.704

Issue date: Feb 2003

Exposure to benzene and risk of leukemia among shoe factory workers

by Seniori Costantini A, Quinn M, Consonni D, Zappa M

Affiliation: UO Epidemiologia ambientale-occupaxionale, CSPO, via di San Salvi 12-50135 Florence, italy. a.seniori@cspo.it

Key terms: benzene; dose-response relationship; exposure; exposure assessment; hematolymphopoietic malignancies; leukemia; risk; shoe factory worker

This article in PubMed: www.ncbi.nlm.nih.gov/pubmed/12630436

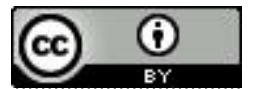




\title{
Exposure to benzene and risk of leukemia among shoe factory workers
}

\author{
by Adele Seniori Costantini, MD, ${ }^{1}$ Margaret Quinn, ScD, ${ }^{2}$ Dario Consonni, MD, ${ }^{3}$ Marco Zappa, MD ${ }^{4}$
}

\begin{abstract}
Seniori Costantini A, Quinn M, Consonni D, Zappa M. Exposure to benzene and risk of leukemia among shoe factory workers. Scand J Work Environ Health 2003;29(1):51-59.
\end{abstract}

\begin{abstract}
Objectives The study attempted to add years of follow-up to an earlier study describing excess leukemia among workers exposed to benzene-based glues in a shoe-factory and to conduct a quantitative exposure assessment of the exposure to benzene and the risk of leukemia.

Methods The cohort comprised 1687 persons with complete work histories, at work on 1 January 1950, and followed through 31 December 1999. For each subject, time-specific cumulative exposure (ppm-years) was calculated as the sum of the products of job-specific concentrations of benzene (ppm) and the duration (years) for each job. Standardized mortality ratios (SMR) were estimated using national and regional rates specific for gender, age, and period.

Results The cumulative exposure ranged from 0 to $>500$ ppm-years. The SMR values for all hematolymphopoietic malignancies and leukemia for the men and women combined were elevated in all but the lowest exposure category. Leukemia risk was significantly elevated in the highest exposure category and the most evident among the men. The SMR values for the men were 1.4 [95\% confidence interval (95\% CI) 0.2-5.0], 3.7 (95\% CI 0.1-20.6), 3.0 (95\% CI 0.4-10.9), and 7.0 (95\% CI 1.9-18.0) for benzene, the cumulative exposure equaling <40, 40-99, 100-199, and >200 ppm-years, respectively.

Conclusions The results indicate that leukemia mortality is associated with exposure to benzene in this factory and that the risk increases with increasing cumulative exposure. The relevance of these findings for estimating risk at much lower levels is limited because of the small study size.
\end{abstract}

Key terms dose-response relationships, exposure assessment, hematolymphopoietic malignancies.

An association between leukemia and occupational exposure to benzene has been described for workers employed in several industries. In 1981, the International Agency for Research on Cancer (IARC) concluded that there was evidence of an association between benzene exposure and the occurrence of acute myeloid leukemia (AML). The evidence was based on case reports in Italy and Turkey (1-3) and on a large epidemiologic study of United States (US) rubber workers conducted by Rinsky et al (4). Subsequent epidemiologic studies have indicated associations between benzene exposure and leukemia (5-11). Some of these studies showed an increased risk for multiple myeloma $(6,8)$. In the update of the study of US rubber workers, an increasing trend with cumulative exposure to benzene was found (6).
Our current study evaluated the risk of mortality from leukemia and other blood malignancies in relation to quantitative estimates of the airborne concentration of benzene among a cohort of workers in a shoe factory in Florence, Italy, where benzene-based glues were used. A previous study in this shoe factory found an excess of leukemia and aplastic anemia among a cohort of 1008 men and 1005 women employed from 1 January 1950 until 31 December 1984 (12). However, for this initial study, no information was available concerning the airborne concentrations of benzene exposure. Little information was available concerning the job titles. Thus it was only possible to use "duration of employment" as the measure of exposure. The initial study calculated standardized mortality ratios (SMR) using the

1 Unit of Occupational-Environmental Epidemiology, Centro per lo Studio e la Prevenzione Oncologica, Florence, Italy.

2 Department of Work Environment, University of Massachusetts Lowell, Lowell, Massachusetts, United States.

3 Department of Occupational Health, Istituti Clinici di Perfezionamento, Milano, Italy.

4 Unit of Clinical and Descriptive Epidemiology, Centro per lo Studio e la Prevenzione Oncologica, Florence, Italy.

Reprint requests to: Dr Adele Seniori Costantini, UO Epidemiologia ambientale-occupazionale, CSPO, via di San Salvi 1250135 Florence, Italy. [E-mail: a.seniori@cspo.it] 
general Italian population to determine the expected number of cases for each outcome. Excesses of leukemia [SMR 4.0, 95\% confidence interval (95\% CI) 1.58.7] and aplastic anemia (SMR 15.7, 95\% CI 5.5-32.6) were found for the male workers only. The cases were concentrated among those employed between 1950 and 1960, the years when it was known that benzene was most used. The mean time since first employment of the cases was 5-10 years. No exposure-response relationships were found between the duration of employment and the risks of leukemia and aplastic anemia. It was concluded that the years in which the cases occurred and the timing of the occurrence of leukemia and aplastic anemia in relation to the time since first employment were consistent with the hypothesis that the disease risk was due to benzene exposure and that further development of the study methods, especially the exposure assessment, was warranted. In addition, it was not known why the disease occurred only among the men. It was hypothesized that the women may have had jobs that resulted in lower benzene exposures $(12,13)$. The cancer mortality of this cohort with an updated follow-up to 1990 was published in the context of a pooled analysis by Fu et al (14).

Given the findings of the initial study, the goals of our present study were to add years of follow-up to the cohort and to conduct a quantitative assessment of the airborne benzene exposure so that the association between benzene and the risk of leukemia and other blood malignancies could be evaluated more precisely. The specific study objectives were (i) to construct a timespecific job-exposure matrix with quantitative estimates of airborne benzene exposure, (ii) to reconstruct the work histories for each member of the cohort using the factory personnel records and interviews with workers, worker representatives, and supervisors of the workers' production departments, (iii) to estimate (using the jobexposure matrix and the work history for each cohort member) the airborne benzene exposure of each worker in the cohort over the entire period that he or she worked in the factory, and (iv) to estimate the risk of leukemia and other blood malignancies in relation to the measures of benzene exposure.

\section{Subjects and methods}

\section{Exposure assessment}

Overview. A technological history of the factory was developed, including its physical structure, production processes and materials, job locations with respect to benzene use within each department, job descriptions, and work practices. Because direct air measurements of benzene were limited, an empirical model was used to make quantitative estimates of exposure for the general room air (the "far-field" benzene exposure) in each department in each year of the study. Comparison of the predicted far-field benzene concentrations with the direct air measurements collected in the far-field was used as a limited validation of the model. The direct measurements were also used to calculate a ratio of the airborne concentration of benzene in the far-field to the concentration in the breathing zone of the workers who handled the benzene-based glues directly (the "nearfield" exposure). This ratio was used to adjust the farfield values predicted by the empirical model to obtain an airborne benzene concentration estimate for specific jobs that handled benzene directly. A job-exposure matrix was then constructed for the period of the study. It was merged with individual work histories, and cumulative benzene exposures were calculated over the entire worklives of all the cohort members.

Description of the factory. The shoe factory began operation in 1939. It had the following departments: cutting, which employed approximately $10 \%$ of the workforce; assembly, employing $25 \%$; the main shoe-making department, employing 58\%; heel making and shearing, employing 5\%; two warehouses, one for raw materials and the other for shipping, together employing $1 \%$; and the administrative offices, employing $1 \%$. The offices were physically separated from the production departments.

Exposure to benzene occurred from the benzenebased glues used to adhere the shoe parts to each other. The benzene-based glues were used primarily in the main shoe-making and assembly departments. The glues were applied manually with brushes dipped in open containers. The primary route for benzene exposure was inhalation, although the potential for skin exposure existed for the workers that performed jobs that required direct glue handling. The workers reported that only a small area of their hands were routinely exposed because the application of the glues required precision. There were reports that solvents were used by some workers occasionally, not routinely, to clean hands at the end of a workshift. Estimates of percutaneous benzene exposure were not made in this study due to the limited amount of available information.

Time periods and locations of benzene use. A natural gum glue containing a very low percentage of benzene (probably not more than $1 \%$ by weight) was used in the assembly department shortly after the factory opened in 1939, until 1954. In this period a small quantity of benzene was also used in two finishing jobs in the main shoe-making department. It was not used elsewhere because the shoe parts were still sewn together by hand. 
Benzene was used on a large scale in the main shoemaking department in 1954 when this department was expanded and the process of gluing the shoe parts was introduced. It was used on a much lower scale in the assembly and the heel making and shearing departments. It was not used directly in the other departments. From 1954 to 1963, three types of glue were used, containing $72 \%, 87.3 \%$, and $84.3 \%$ benzene by weight. The average percentage of benzene in these glues, $81 \%$, was used to estimate the benzene exposure because the three glues were used interchangeably. In 1963, an Italian law was passed to limit the amount of benzene in glues to $2 \%$ by weight. However, factory manager interviews indicated that, while the lower percentage benzene glues were being introduced, the glues containing the higher percentages of benzene were used through 1965, in order to deplete the old stores. After 1965, benzene-based glues were replaced entirely.

\section{Empirical model to estimate the concentration of airborne} benzene by department. The concentration of benzene in the general room air was estimated for each department workroom for each year of the study. The annual concentrations of benzene in the air of each workroom were assumed to be a function of the evaporation rate of benzene, estimated using the quantity of benzene applied per shoe and the annual shoe production rates; the airflow in each workroom, estimated using the workroom volume, the number of air changes per minute, and a factor to convert grams of benzene per liter of air to parts per million (ppm). This information was used in the following standard dynamic equilibrium concentration equation (15):

$$
C=\left(E \times 24.5 \times 10^{6}\right) / M W \times Q,
$$

where $C=$ concentration of airborne benzene in a particular workroom (ppm), $E=$ benzene evaporation rate in a workroom $(\mathrm{g} / \mathrm{min}), 24.5=$ liters $/$ mole of gas at standard temperature and pressure, $M W=$ molecular weight of benzene $(78 \mathrm{~g} / \mathrm{mole})$, and $Q=$ ventilation rate for a particular workroom $(1 / \mathrm{min})$.

The predicted values of $C$ were called the "far-field" exposures because they represented the airborne benzene concentration throughout a workroom, according to the assumption of complete mixing and an equilibrium between the benzene evaporation rate and the room ventilation. Because complete mixing does not occur instantaneously, near-field and mid-field exposures were also estimated for specific jobs that handled benzene directly (near-field) or that worked next to a job that handled benzene (mid-field). (See the exposure assignments given later by job.) A description of the main factors used for the empirical model follows.

With respect to the quantities of benzene used, engineers from the factory estimated that 20 grams of ben- zene-based glue were used in the main shoe-making department per pair of shoes produced. Thus it was estimated that 16.2 grams of benzene were used per pair of shoes $(20 \mathrm{~g} \times 81 \%=16.2 \mathrm{~g})$. Records indicating the number of shoes produced per year were available both from public and factory documents. The shoe production rate was fairly constant from 1954 until 1959. It nearly doubled in 1960, and then began to decline in the early 1960s. Production workers and engineers estimated that the quantity of benzene-based glue used in the assembly and in the heel making and shearing departments was approximately one-tenth that of the main shoe-making department and that only a few jobs in these departments used benzene directly. Benzene was not used in the other departments.

Benzene is a liquid with a high vapor pressure, and it is emitted into workroom air by evaporation. Information from the interviews indicated that the glues dried within an hour, consistent with the high volatility of benzene. Because there was no local exhaust ventilation and the shoes were placed on open racks to dry in the workrooms, it was assumed that all of the benzene used in a workroom evaporated into it. The evaporation rate was thus the total grams of benzene used in a particular workroom in 1 day divided by 480 minutes, the length of the single, 8-hour shift employed in the factory. For example, in a year when the shoe production in the factory was 2127 pairs/day, the evaporation rate of benzene was calculated in the main shoe-making department as 2127 pairs/day $\times 16.2$ grams benzene/pair $=$ $34.4 \mathrm{~kg}$ of benzene evaporated/day.

Prior to 1954, the main shoe-making department, which employed most of the workers, was organized in a single production line in one large room. The shoe components were transported manually through each step of the production process. In 1954 two large mechanized assembly lines were introduced. The mechanized lines required the location of the jobs to be fixed and at a uniform distance from one another. Although the shapes of the lines were different, the two lines were similar in the type, order, and number of jobs located along them and in the total number of shoes produced. The configuration of the assembly lines and many of the jobs located along the lines were visible in photographs available to the investigators.

The volume of each department workroom was calculated from detailed blueprints for each period of construction. The ventilation rate for each year of the study was estimated using the volume of each workroom and the air changes per minute estimated to move through that room volume given the type of ventilation in the workroom. Both natural ventilation via windows and doors (different in summer and winter) and mechanical ventilation were considered. From 1954 to 1960, the ventilation in the main shoe-making department was 
from helical fans. In 1960 and 1961, new fans were added that increased the ventilation rate. In 1962, the room volume of the main shoe-making department was increased, and a central air supply system was installed that increased the general room ventilation. Through all of these time periods, the shoes were placed on racks in the open workroom to dry with no local exhaust ventilation.

Exposure assignments by job within department and construction of the job-exposure matrix. Each job was located within a department according to information gathered in worker and manager interviews, from factory production records, and from examinations of photographs taken of various departments in the 1960s. The most-detailed job-location work was required for identifying the job order on the assembly lines of the main shoe-making department. A total of 43 jobs per department pairs were identified. Factory records, photographs, and worker interviews were used to identify which jobs used the benzene-based glues directly; these jobs were assigned to the "near-field" with respect to benzene exposure. Jobs that were located next to a job that handled benzene, but which did not involve direct handling of the benzene-based glues, were assigned to the "mid-field." Jobs that neither involved handling benzene directly nor were located next to a job that involved handling benzene were assigned to the "far-field." Jobs that were in locations physically separated from the production departments where benzene-based glues were used were assigned zero exposure. A job-exposure matrix was constructed to assign a concentration of airborne benzene to each job within each production department for each year of the study by linking the quantitative estimates of airborne benzene for each department workroom with information about whether the jobs were in the near-, mid- or far-fields.

Use of direct measurements. The only air sampling data available during the years of high benzene use were those obtained with seven Dræger tube measurements collected by a labor inspector in January 1961 in the main shoe-making department. The measurement error of the Dræger tubes was $\pm 20 \%$. Four general area Dræger tube samples were collected at distances greater than 9 meters (the far-field) from a worker performing a job that required the direct application of benzenebased glue. The values of the sample ranged from 15 to $20 \mathrm{ppm}$. Two additional Dræger tube samples were collected in the breathing zones of glue applicators (nearfield); their values were 35 and $45 \mathrm{ppm}$. One Dræger tube measurement of $25 \mathrm{ppm}$ was taken in the breathing zone of a worker that did not handle glue directly but was located next to the glue applicator's job, at a distance of approximately 3 meters (mid-field). Two additional samples collected by a labor inspector in December 1962 for a mid-field job had a value of $25 \mathrm{ppm}$. Thirty-three measurements collected in 1963 indicated that most far-field exposures were approximately $\leq 6$ ppm. Bulk analyses of two new glues (ie, purchased after the 1963 law limiting benzene in glues to $2 \%$ by weight) found benzene concentrations of $2.7 \%$ and $3.9 \%$ by weight. The other solvents in the bulk samples were hexane and heptane. Thirty-two measurements collected in 1965 did not detect benzene. Bulk analyses of the glues revealed no benzene and varying amounts of hexane, heptane, and toluene. The sampling method and the limit of detection for the 1963 and 1965 measurements were unknown. The direct measurements were used in the following four ways: (i) to provide a limited validation of the empirical model developed to predict the farfield benzene concentrations, (ii) to calculate the ratio of the airborne concentration of benzene in the far-field to that in the near-field or breathing zone of workers performing jobs that used benzene directly, (iii) to support the approach for calculating mid-field exposure, and (iv) to identify when benzene was no longer present in the factory.

Based on these limited data, the ratio of near- to farfield benzene concentrations was estimated to be 2 to 1. The predicted far-field benzene concentration for the main shoe-making department was 14 ppm in 1961, a value similar to the result of the far-field Dræger tube measurements for the same department and year (15$20 \mathrm{ppm})$. The far-field exposures predicted by the empirical model were multiplied by the near- to far-field ratio of 2 to obtain the near-field benzene concentrations. The mid-field benzene concentrations were the average of the near- and far-field estimates. Reports that benzene-based glues were used through 1965 and then replaced entirely with other solvents were substantiated by the 1963 and 1965 air and bulk sampling measurements.

\section{Reconstruction of the cohort work histories}

The personnel office of the factory provided the dates for the beginning and end of each job held by each worker. However, these work histories were only complete for 457 workers. Therefore, it was necessary to reconstruct the remaining work histories by means of interviewing long-term workers who could remember the organization of work and the working population of the factory. Lists of names of people for whom no job information was available at the personnel office were given to three employees (the foremen of the personnel office, the main shoe production department, and the assembly department). After these interviews, job histories were constructed for another 698 persons. A second round of interviews was then conducted to gather 
the remaining work histories. Interviews were conducted with the foremen of the heel production department, the raw materials department, and the shipping department. This second round of interviews provided work history information for another 532 workers. In the end, work history information was collected for 1687 subjects $(84 \%$ of all workers employed during the study period). The interviewees were not told about the health status of the workers for whom the work histories were sought. The interviewees may have been aware of some of the cases of leukemia that occurred among the employees while still at work, and it is possible that this knowledge may have affected their recall of job information. However, cases occurring after retirement were, in general, not known to the interviewees.

In an attempt to investigate potential recall bias, work history data were gathered on 100 of the workers independently from two different interviewees. The agreement between the two was excellent. For $2 \%$ of the 100 workers, the two different interviewees assigned them to completely different departments, and for an additional 3\%, there was agreement on the department, but not on the specific job held. For all the other workers, the two interviewees agreed on both job and department. For the workers with discrepant information, the assignment of the interviewee who worked more closely in time with the worker was accepted.

Work history information was obtained from worker interviews for 17 of the 18 cases of hematolymphopoietic malignancies. For the case not known to the interviewees, the clinical records were the only source of work history information.

\section{Cohort and case definition}

The final cohort consisted of 1687 persons followed from 1 January 1950 to 31 December 1999. The vital status was ascertained from the official register of the municipality of residence. The cause of death was obtained from the regional mortality register for residents of Tuscany. For decedents who had resided outside Tuscany, the death certificate was obtained from the official municipal register. In this situation the cause of death was classified by the physician responsible for coding the regional mortality register.

\section{Estimation of cumulative and peak exposure}

For each subject, time-specific cumulative exposure (ppm-years) was calculated as the sum of the products of the job-specific concentrations of benzene (ppm) and the duration (years) of each job. The intensity of the benzene exposure (ppm) was obtained from the job-exposure matrix. Job titles and duration were obtained from the work histories. In the cases in which only a worker's department was known, but not the specific job, the far-field exposure for the department was used to estimate cumulative exposure. A peak exposure metric was also estimated using the highest intensity of benzene exposure (ppm) experienced by a worker; duration of exposure was not accounted for in this metric.

\section{Statistical analysis}

A slightly modified version of the SAS program written by Pearce \& Checkoway was utilized to allocate person-years of cumulative exposure and other relevant covariate categories in order to estimate the association between exposure and the risk of hematolymphopoietic malignancies $(16,17)$. Standardized mortality ratios (SMR) and their exact 95\% confidence intervals (95\% CI) were calculated using Stata Statistical Software (18). Analyses were performed separately for all the blood malignancies and for leukemia only. National (19501969) and regional (1970-1993) rates specific for 5-year calendar periods and 5-year age classes were used to calculate the expected cases. An internal analysis using Poisson regression was also performed using Stata Statistical Software (18). Strata were made of 5-year age classes and 5-year calendar periods.

\section{Results}

The estimated far-field exposure in the main shoe-making department was $0.6 \mathrm{ppm}$ in 1939-1953, $29 \mathrm{ppm}$ in 1954-1958, $27 \mathrm{ppm}$ in 1959, $42 \mathrm{ppm}$ in 1960, $14 \mathrm{ppm}$ in 1961, 12 ppm in 1962-1963, 1 ppm in 1964 and 1965, and $0 \mathrm{ppm}$ after 1965 . The near-field exposures were twice these concentrations. The estimated airborne benzene concentrations, including the near- and far-field assignments, ranged from 0 to $92 \mathrm{ppm}$. The highest exposures were confined to the years 1954-1960. Cumulative exposure to benzene among the cohort members ranged from 0 to $>500 \mathrm{ppm}$-years (table 1 ). On the average, the women experienced cumulative exposures that were considerably lower than those of the men. For example, the median cumulative exposure for the women was 4.4 ppm-years, while that of the men was 14.7 ppm-years. The mean cumulative exposures were 43.4 and $71.8 \mathrm{ppm}$-years for the women and men, respectively.

For the cohort analysis, cumulative exposures were divided into four categories resembling those used by Rinsky and his colleagues (6) in the US rubber worker study: <40, 40-99, 100-199, and $\geq 200$ ppm-years. The first category ( $<40 \mathrm{ppm}$-years) was chosen to facilitate comparisons with the Rinsky study and also because 40 ppm-years is the cumulative exposure that will result from exposure to an average intensity of $1.0 \mathrm{ppm}$ (the 
Table 1. Cumulative exposure (ppm-years) for the cohort at the end of the follow-up. (ppm = parts per million)

\begin{tabular}{lcccccrc}
\hline & \multicolumn{7}{c}{ Cumulative exposure (ppm-years) } \\
\cline { 3 - 8 } Gender & Number & Mean & SD & Range & 25th percentile & Median & 75th percentile \\
\hline Male & 891 & 71.8 & 100.4 & $0-522.4$ & 0 & 14.7 & 125.6 \\
Female & 796 & 43.4 & 83.7 & $0-488.1$ & 0 & 4.4 & 39.3 \\
\hline Total & 1687 & 58.4 & 93.9 & $0-522.4$ & 0 & 8.2 & 84.9 \\
\hline
\end{tabular}

Table 2. Characteristics of the 18 cases of hematolymphopoietic cancer. (ppm = parts per million)

\begin{tabular}{|c|c|c|c|c|c|c|c|c|c|c|c|}
\hline & $\begin{array}{l}\text { Year of } \\
\text { birth }\end{array}$ & $\begin{array}{l}\text { Year of } \\
\text { death }\end{array}$ & ICD VIII & $\begin{array}{l}\text { a Job } 1 \\
\text { code }^{b}\end{array}$ & Period of job $1^{c}$ & $\begin{array}{l}\text { Job } 2 \\
\text { code }\end{array}$ & Period of job 2 & $\begin{array}{l}\text { Job } 3 \\
\text { code }\end{array}$ & Period of job 3 & Gender & $\begin{array}{l}\text { Cumulative } \\
\text { exposure } \\
\text { (ppm-years) }\end{array}$ \\
\hline 1 & 1920 & 1957 & 2070 & 80245 & 02/1954-07/1955 & . & . & . & . & Male & 41.2 \\
\hline 2 & 1924 & 1963 & 2070 & 80245 & 09/1950-07/1963 & . & . & . & . & Male & 251.9 \\
\hline 3 & 1923 & 1964 & 2079 & 80262 & 02/1953-11/1964 & . & . & . & . & Male & 380.4 \\
\hline 4 & 1913 & 1964 & 2072 & 80245 & 01/1959-03/1964 & . & . & . & . & Male & 108.2 \\
\hline 5 & 1902 & 1971 & 2070 & 80245 & 02/1941-08/1946 & 80245 & 02/1947-06/1962 & . & . & Male & 245.4 \\
\hline 6 & 1932 & 1978 & 2022 & 80245 & 07/1957-0719/63 & 80260 & 01/1964-09/1964 & 32100 & 10/1969-12/1978 & Male & 147.2 \\
\hline 7 & 1915 & 1981 & 2030 & 80200 & 02/1948-06/1949 & 80245 & 01/1956-06/1969 & · & $\cdot$ & Female & 197.7 \\
\hline 8 & 1911 & 1982 & 2079 & 80245 & $10 / 1957-06 / 1963$ & . & . & . & . & Male & 140.4 \\
\hline 9 & 1902 & 1985 & 2000 & 80245 & 01/1955-07/1971 & 80295 & 12/1971-07/1977 & . & . & Male & 226.5 \\
\hline 10 & 1947 & 1986 & 2051 & 80215 & $11 / 1964-11 / 1969$ & $\cdot$ & $\cdot$ & . & . & Male & 0.1 \\
\hline 11 & 1920 & 1987 & 2030 & 80257 & 07/1956-02/1963 & . & . & . & . & Male & 255.6 \\
\hline 12 & 1909 & 1988 & 2070 & 80234 & 08/1939-06/1940 & 80234 & 08/1940-06/1964 & . & . & Female & 98.8 \\
\hline 13 & 1926 & 1990 & 2030 & 80226 & 07/1957-12/1984 & $\cdot$ & $\cdot$ & . & . & Male & 12.9 \\
\hline 14 & 1919 & 1994 & 2041 & 80245 & 09/1953-03/1955 & . & . & . & . & Male & 36.5 \\
\hline 15 & 1939 & 1995 & 2050 & 80226 & 02/1954-08/1965 & 80233 & 09/1966-01/1971 & . & . & Female & 22.8 \\
\hline 16 & 1931 & 1996 & 2041 & 80245 & 09/1950-10/1967 & 80241 & $11 / 1967-03 / 1979$ & . & . & Male & 259.0 \\
\hline 17 & 1936 & 1997 & 2028 & 0 & 01/1954-07/1955 & 80245 & $12 / 1955-02 / 1961$ & . & . & Female & 162.6 \\
\hline 18 & 1921 & 1999 & 2028 & 80245 & 03/1965-09/1975 & · & $\cdot$ & . & . & Male & 0.8 \\
\hline
\end{tabular}

${ }^{a}$ Cause of death coded according to the International Classification of Disease (eighth revision).

b Numeric codes assigned to each unique job-department combination. See the text.

c Dates of starting and stopping each job, month/year.

Table 3. Standardized mortality ratios (SMR) and 95\% confidence intervals $(95 \% \mathrm{Cl})$ by categories of cumulative exposure for the men and women combined. (ppm = parts per million)

\begin{tabular}{|c|c|c|c|c|c|c|c|c|}
\hline \multirow[b]{2}{*}{ Cumalative exposure } & \multicolumn{4}{|c|}{ All blood malignancies } & \multicolumn{4}{|c|}{ Leukemia } \\
\hline & Observed cases & Expected cases & SMR & $95 \% \mathrm{Cl}$ & Observed cases & Expected cases & SMR & $95 \% \mathrm{Cl}$ \\
\hline$<40$ ppm-years & 5 & 5.57 & 0.9 & $0.3-2.1$ & 3 & 2.36 & 1.3 & $0.3-3.7$ \\
\hline 40-99 ppm-years & 2 & 1.15 & 1.7 & $0.2-6.3$ & 2 & 0.49 & 4.1 & $0.5-14.7$ \\
\hline 100-199 ppm-years & 5 & 1.76 & 2.8 & $0.9-6.6$ & 2 & 0.79 & 2.5 & $0.3-9.1$ \\
\hline$\geq 200$ ppm-years & 6 & 1.75 & 3.4 & $1.3-7.5$ & 4 & 0.79 & 5.1 & $1.4-13.0$ \\
\hline
\end{tabular}

standard proposed by the European Union) for a 40-year worklife. The cohort members in this lowest exposure category contributed the majority of person-years (59.6\% of the person-years for the men and $73.5 \%$ of the person-years for the women). The cases of hematolymphopoietic cancers, all but four of them among the men, had generally high cumulative exposures, when compared with the entire population (table 2). Only two cases had a cumulative exposure below the median, and four others had a cumulative exposure below the mean.

The standardized mortality ratios for hematolymphopoietic malignancies and leukemia for the men and women combined were elevated in all but the lowest cumulative exposure category (table 3 ). That for leukemia among the men reached 7.0 in the highest cumulative exposure stratum (table 4). An alternative analysis 
Table 4. Standardized mortality ratios (SMR) and 95\% confidence intervals (95\% $\mathrm{Cl})$ by categories of cumulative exposure for the men. (ppm = parts per million)

\begin{tabular}{|c|c|c|c|c|c|c|c|c|}
\hline \multirow[b]{2}{*}{ Cumalative exposure } & \multicolumn{4}{|c|}{ All blood malignancies } & \multicolumn{4}{|c|}{ Leukemia } \\
\hline & Observed cases & Expected cases & SMR & $95 \% \mathrm{Cl}$ & Observed cases & Expected cases & SMR & $95 \% \mathrm{Cl}$ \\
\hline$<40$ ppm-years & 4 & 3.34 & 1.2 & $0.3-3.1$ & 2 & 1.45 & 1.4 & $0.2-5.0$ \\
\hline 40-99 ppm-years & 1 & 0.62 & 1.6 & $0.04-9.0$ & 1 & 0.27 & 3.7 & $0.1-20.6$ \\
\hline 100-199 ppm-years & 3 & 1.43 & 2.1 & $0.4-6.1$ & 2 & 0.66 & 3.0 & $0.4-10.9$ \\
\hline$\geq 200$ ppm-years & 6 & 1.23 & 4.9 & $1.8-10.6$ & 4 & 0.57 & 7.0 & $1.9-18.0$ \\
\hline
\end{tabular}

Table 5. Standardized mortality ratios (SMR) and 95\% confidence intervals (95\% CI) by categories of peak exposure for leukemia. (ppm = parts per million)

\begin{tabular}{|c|c|c|c|c|c|c|c|c|}
\hline \multirow[b]{2}{*}{ Peak exposure } & \multicolumn{4}{|c|}{ Men and women } & \multicolumn{4}{|c|}{ Men } \\
\hline & Observed cases & Expected cases & SMR & $95 \% \mathrm{Cl}$ & Observed cases & Expected cases & SMR & $95 \% \mathrm{Cl}$ \\
\hline$<1 \mathrm{ppm}$ & 1 & 1.2 & 0.8 & $0.02-4.7$ & 1 & 0.8 & 1.2 & $0.03-6.7$ \\
\hline $1-29 \mathrm{ppm}$ & 4 & 1.5 & 2.6 & $0.7-6.8$ & 2 & 0.8 & 2.5 & $0.3-9.1$ \\
\hline$\geq 30 \mathrm{ppm}$ & 6 & 1.7 & 3.5 & $1.3-7.6$ & 6 & 1.3 & 4.5 & $1.1-9.9$ \\
\hline
\end{tabular}

was conducted, categorizing the cohort by estimated peak benzene exposure intensity (table 5). The following three categories of "peak exposure" were identified: $<1 \mathrm{ppm}, 1-29 \mathrm{ppm}$, and $\geq 30 \mathrm{ppm}$. Elevated risk was associated with high peak exposures, especially those over $30 \mathrm{ppm}$.

In an internal analysis that controlled for gender, age, and calendar year, cumulative exposure was positively associated with the risk of leukemia and all blood malignancies. The rate ratios (RR) for leukemia were 3.0 (95\% CI 0.5-19.6), 2.1 (95\% CI 0.3-13.6), and 4.7 (95\% CI 0.9-24.0) for 40 -99, 100-199, and $\geq 200$ ppm-years of benzene, respectively. Discrepancies with the standardized mortality ratios could have been the result of the small numbers, given that standardized mortality ratios are more stable because they are based on rates of the general population.

\section{Discussion}

Benzene was used extensively as a solvent in glues in this Italian shoe factory for a well-defined period of time in the 1950s and 1960s. Leukemia cases were identified among the workers in this factory, starting in 1957. To gain a better understanding of the nature of the leukemia risk from the exposures experienced by these workers, a quantitative exposure reconstruction was undertaken using an empirical model of the factory environment and shoe production. Airborne benzene estimates based on the empirical modeling were found to be similar to the few existing direct air measurements of benzene.
The other critical component of the individual exposure assessment was the job information, most of which was obtained from interviews with long-term workers. It is possible that inaccuracies entered the exposure estimation through incomplete or biased recall. An agreement study in which information regarding 100 workers' jobs and departments was collected independently from two different interviewees provided some reassurance that the extent of recall bias was likely to have been small.

While uncertainties about the benzene exposure in this shoe factory remain, we were able to use the limited data to make quantitative estimates of lifetime benzene exposure. By choosing a quantitative reconstruction rather than a semi-quantitative (low, medium, high) approach, we could more readily compare the results to the findings of other studies, and this comparison may be useful for risk assessment and standard setting. While there is undoubtedly imprecision in the cumulative exposure estimates, we do not think that it invalidates the leukemia risk estimates presented. On the contrary, the consistency with the data of Rinsky and his colleagues in the US rubber worker study suggests that this study can make a useful contribution to the literature on quantitative benzene exposure-response, which is still, unfortunately, limited.

The airborne benzene concentrations were estimated to have ranged from 0 to $92 \mathrm{ppm}$. These levels are in the range of the benzene exposure estimates made in other work environments in which leukemia excesses have been observed (6-11). One strength of this setting for the evaluation of cancer risks was the existence of information with which to pinpoint clearly the time 
period, the departments, and the jobs in which benzenebased glues were used. Thus this exposure assessment yielded a fairly large range of cumulative exposures. This range in turn enhanced the statistical power of this admittedly small study.

There were only 18 hematolymphopoietic cancers observed in this cohort. Such small numbers make it difficult to observe trends in risk across exposure categories, but such evidence was indeed found in these data. The standardized mortality ratio for leukemia among the men reached 7.0 in the highest cumulative exposure stratum-those with $\geq 200$ ppm-years. Below 40 ppm-years, there was limited evidence of excess risk, although, as in all the other exposure strata, the confidence interval was wide.

There were only four cases among the women, and therefore it was difficult to draw conclusions about gender differences in risk. There is some very limited evidence that women were at lower risk, however. If so, it is difficult to say whether the lower exposures experienced by the women may have explained the difference. There are no known biological reasons that explain a lower susceptibility to the carcinogenic effects of benzene among the women. On the contrary, it has been suggested that women, on the average, may incur a modestly higher internal benzene dose for the same exposure as the men's (19). It is also possible that the men might have had additional sources of exposure to benzene that were not estimated by the exposure model (eg, unrecorded overtime work or a second job), or they may have had more skin contact with the glues during work. It was reported that male workers occasionally washed their hands at the end of the workday with solvents. The potential for significant benzene absorption through the skin has been cited in several studies $(20,21)$. A limitation of this exposure assessment was that percutaneous benzene exposure was not estimated because the necessary historical documentation was unavailable.

Evidence for an exposure-risk association was observed with both the peak exposure metric and the cumulative exposure metric. It is difficult to interpret this finding because the two exposure measures, peak and cumulative exposure, were highly correlated. For reasons of consistency with previous studies, and biologic plausibility, the results using the cumulative exposure metric seem more relevant.

A few studies have reported the dose-related incidence or mortality of leukemia $(6,8,11)$. The most important previous study of benzene and leukemia risk is that reported by Rinsky and his colleagues (1987) for US rubber workers (6). The exposure-risk trends reported for that cohort and those of our study are in remarkably good agreement (figure 1). The only important difference between the two sets of results is the lack, in our study, of a cumulative exposure category corresponding to the highest exposure group in the Rinsky study - those with $\geq 400$ ppm-years. In all other respects, the two sets of results are entirely consistent, despite the difficulties of exposure reconstruction and the very limited number of cases in our study.

In conclusion our study indicates that the leukemia mortality in the factory studied was associated with exposure to benzene and that the risk increased with increasing cumulative benzene exposure. The relevance of these findings for estimating risk at much lower levels is limited because of the small study size.

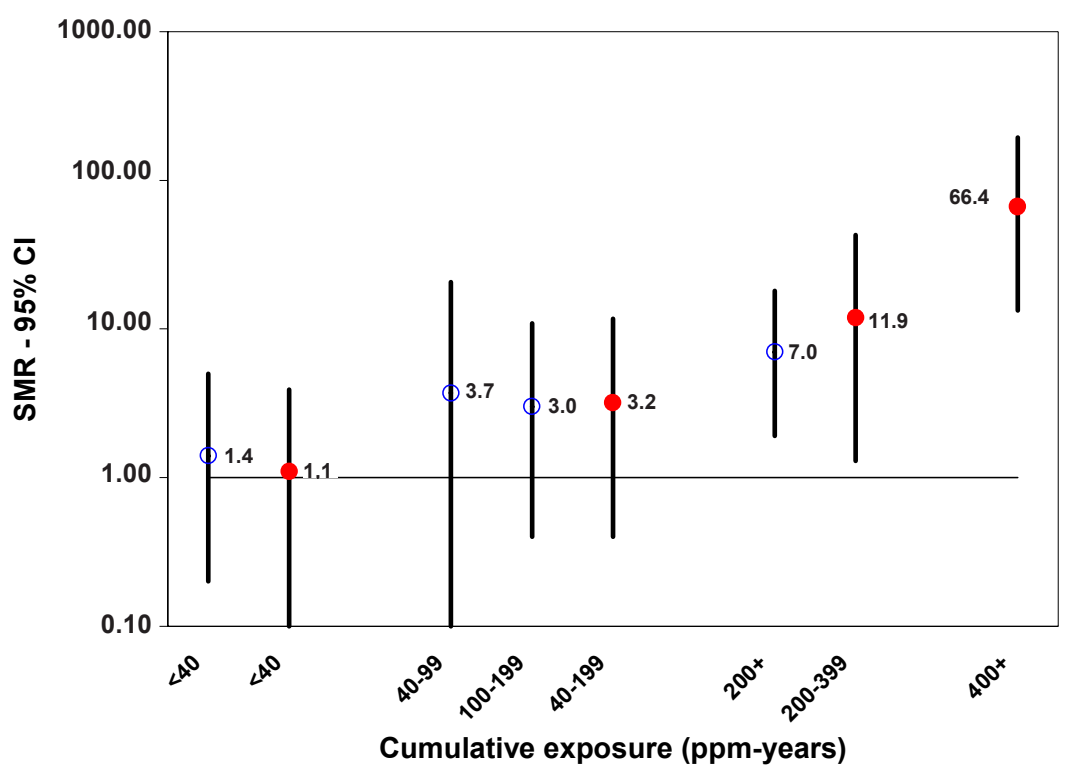

Figure 1. Standardized mortality ratios (logscale) for the categories of cumulative exposure to benzene. The results of the study (open circles) are compared with those from the Rinsky et al study (6) of United States rubber workers (closed circles). (Error bars = $95 \%$ confidence intervals) 


\section{Acknowledgments}

We thank Dr David Kriebel for his helpful contribution to the statistical analyses.

We also thank the factory council and the management of the factory for their assistance in the collection of data and the reconstruction of the history of the plant. Thanks are also extended to Ilario Ceccarelli, Lanfranco Gaddini, Graziella Lepri, Emilio Lombini, Paola Martinelli, Marcello Pancrazi, Giorgio Trippoli, and especially Danilo Mattolini, who contributed vital information about the organization of work in the factory and about the job histories of cohort members.

\section{References}

1. Vigliani EC, Saita G. Benzene and leukemia. N Engl J Med 1964;271:872-6.

2. Vigliani EC, Forni A. Benzene and leukemia. Environ Res 1976;11:122-7.

3. Aksoy M, Erdem S, DinÇol G. Leukemia in shoe-workers exposed cronically to benzene. Blood 1974;6:837-41.

4. Rinsky RA, Young RJ, Smith AB. Leukemia in benzene workers. Am J Ind Med 1981;2:217-45.

5. Bond GG, Mc Laren EA, Baldwin CL, Cook RR. An update of mortality among chemical workers exposed to benzene. Br J Ind Med 1986;43:685-91.

6. Rinsky RA, Rinsky MS, Smith AB, Hornung R, Filloon TG, Young RJ, et al. Benzene and leukemia. N Engl J Med 1987; 17:1044-50.

7. Yin S-N, Li G-L, Tain F-D, Fu Z-I, Jin C, Chen Y-J, et al. Leukemia in benzene workers: a restrospective cohort study. Br J Ind Med 1987;44:124-8.

8. Wong O. Risk of acute myeloid leukaemia and multiple myeloma in workers exposed to benzene. Occup Environ Med 1995;52(6):380-4.

9. Yin SN, Hayes RB, Linet M, Li GL, Dosemeci M, Travis LB, et al. An expanded cohort study of cancer among benzene exposed workers in China. Environ Health Perspect 1996;104 suppl 6:1339-41.
10. Hayes RB, Yin SN, Dosemeci M, Li GL, Wacholder S, Chow $\mathrm{WH}$, et al. Mortality among benzene-exposed workers in China. Environ Health Perspect 1996;104 suppl 6:1349-52.

11. Hayes RB, Yin SN, Dosemeci M, Li GL, Wacholder, Travis $\mathrm{LB}$, et al. Benzene and the dose-related incidence of hematologic neoplasms in China: Chinese Academy of Preventive Medicine - National Cancer Institute Benzene Study Group. J Natl Cancer Inst 1997;89(14):1065-71.

12. Paci E, Buiatti E, Seniori Costantini A, Miligi L, Pucci N, Scarpelli A, et al. Aplastic anemia, leukemia and other cancer mortality in a cohort of shoe workers exposed to benzene. Scand J Work Environ Health 1989;15:313-8.

13. Paci E, Buiatti E, Seniori Costantini AR, Miligi L, Quinn M, Kaldor J, et al. Leukemia and aplastic anemia in a shoeworker cohort exposed to benzene. In: Hogstedt C, Reuterwall C, editors. Progress in occupational epidemiology: proceedings of the Sixth International Symposium on Epidemiology in Occupational Health; 1988 Aug 16-19, Stockolm, Sweden. Amsterdam: Elseviers Science Publishers BV; 1988. p 133-5.

14. Fu H, Demers PA, Seniori Costantini A, Winter P, Colin D, Kogevinas M, et al. Cancer mortality among shoe manufacturing workers: an analysis of two cohorts. Occup Environ Med 1996;53(6):394-8.

15. American Industrial Hygiene Association. Engineering field reference manual; chapter 1 (Concentrations-particulates, vapors and gases). Akron (OH): American Industrial Hygiene Association; 1984. p 6.

16. Pearce N, Checkoway H. A simple computer program for generating person-time data in cohort studies involving timerelated factors. Am J Epidemiol 1987;125:1085-91

17. SAS Institute Inc. SAS Language: reference, release 8.1. Cary (NC): SAS Institute Inc; 1999.

18. Stata Corporation. Stata statistical software; release 7.0. College Station (TX): Stata Corporation; 2001.

19. Brown EA, Shelley ML, Fisher JW. A pharmacokinetic study of occupational and environmental benzene exposure with regard to gender. Risk Anal 1998;18(2):205-13.

20. Brenner D, Kalnas J, Teitelbaum DT. Skin absorption of benzene as a contaminant in other solvents. Eur J Oncol 1998;4:399-405.

21. Kalnas J, Teitelbaum DT. Dermal absorption of benzene: implications for work practices and regulations. Int J Occup Environ Health 2000;6(2):114-21.

Received for publication: 29 August 2002 